\title{
Squamous cell carcinoma of the scrotum in HIV: two case reports
}

\author{
Jeff John ${ }^{1 *}\left(\mathbb{D}\right.$, Ken Kesner $^{1}$ and John Lazarus ${ }^{2}$
}

\begin{abstract}
Background: Squamous cell carcinoma (SCC) of the scrotum was the first malignancy known to be associated with exposure to an occupational carcinogen -in this case, soot trapped in the breeches of chimney sweeps. Better civil rules and regulations and the replacement of hearths with other forms of heating have rendered SCC of the scrotum a rarity. We report two cases of scrotal SCC with vastly differing clinical presentations and management.

Case presentation: Case 1 had T1 NO MO disease and presented with a small $(<2 \mathrm{~cm})$, innocuous-looking, non-healing ulcer of eight years duration. A punch biopsy revealed a superficially invasive SCC confirmed on immunohistochemical profiling. A wide local excision of the lesion was subsequently performed. Follow-up at three years showed no signs of recurrence. Case 2 presented with T4 N1 M1 disease and rapidly progressing locally destructive mass. A punch biopsy of the scrotal lesion confirmed invasive moderately differentiated focally keratinising SCC. The metastatic evaluation confirmed the presence of metastatic, extensive para-aortic lymphadenopathy. He was managed with cisplatin-based chemoradiotherapy.

Conclusion: Early detection and management of patients with SCC of the scrotum are essential. If the diagnosis is delayed, treatment options become limited, and the prognosis is poor. Notwithstanding the rarity of this disease, multicentre trials are needed to provide more precise guidelines as to the optimal management of these patients.
\end{abstract}

\section{Background}

Squamous cell carcinoma (SCC) of the scrotum was the first malignancy known to be associated with exposure to an occupational carcinogen-in this case, soot trapped in the breeches of chimney sweeps [1]. Chimney sweeps are a thing of the past, but those who work with distillates of coal and mineral oil remain at increased risk of scrotal SCC. Better civil rules and regulations and the replacement of hearths with other forms of heating have rendered SCC of the scrotum a rarity [2]. We report two cases of scrotal SCC with vastly differing clinical presentations and management.

\footnotetext{
${ }^{*}$ Correspondence: jeffveenajohn@gmail.com

1 Division of Urology, Department of Surgery, Frere Hospital and Walter

Sisulu University, East London 5200, South Africa

Full list of author information is available at the end of the article
}

\section{Case presentation}

\subsection{Case 1}

A 51-year-old, unemployed, African male was referred to the urology unit with a non-healing, painful ulcer of the scrotal skin, of eight years duration. He had been diagnosed with HIV, 15 years earlier and been fully compliant with his antiretroviral therapy ever since. His current viral load was lower than the detectable limit. Clinically, he appeared generally well with a small, 2 -cm superficial ulcer at the base of the left hemiscrotum (Fig. 1) with no palpable inguinal lymphadenopathy. Initial blood work, including full blood count, urea, creatinine and electrolytes were unremarkable. A punch biopsy revealed a superficially invasive SCC confirmed on immunohistochemical profiling. A wide local excision of the lesion was subsequently performed. His postoperative period was uneventful, and he was discharged a day later. Follow-up at three years showed no signs of recurrence. 


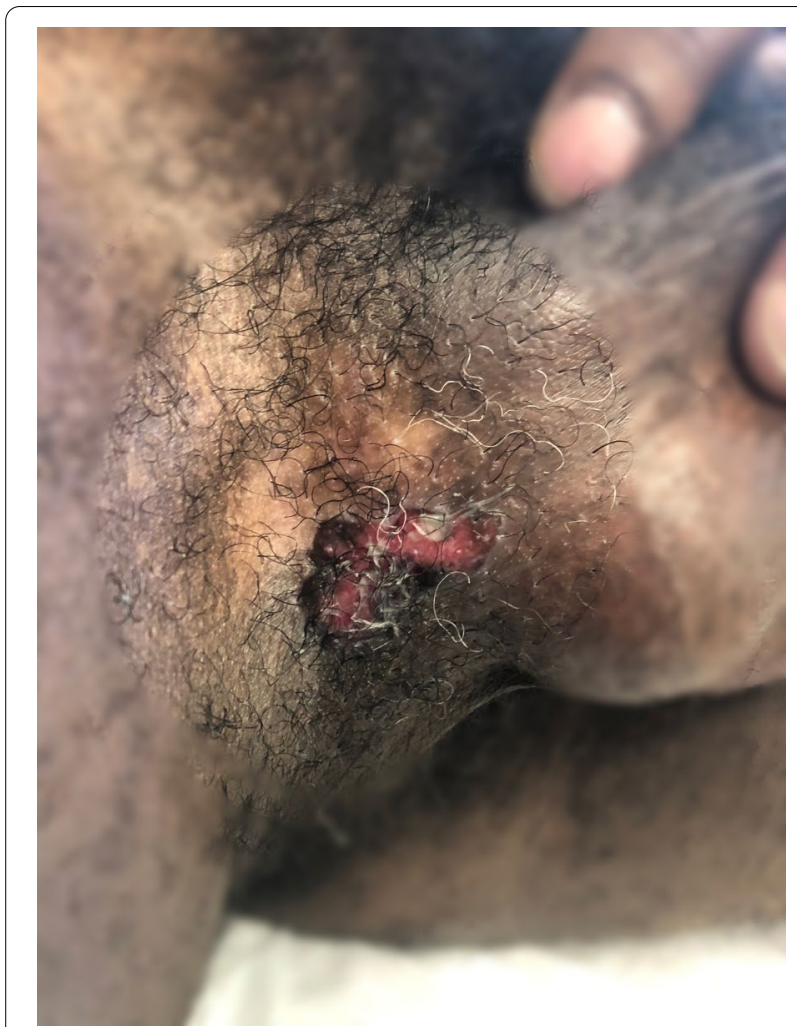

Fig. 1 Pre-operative photograph showing a small, $2 \mathrm{~cm}$ superficial ulcer at the base of the left hemiscrotum

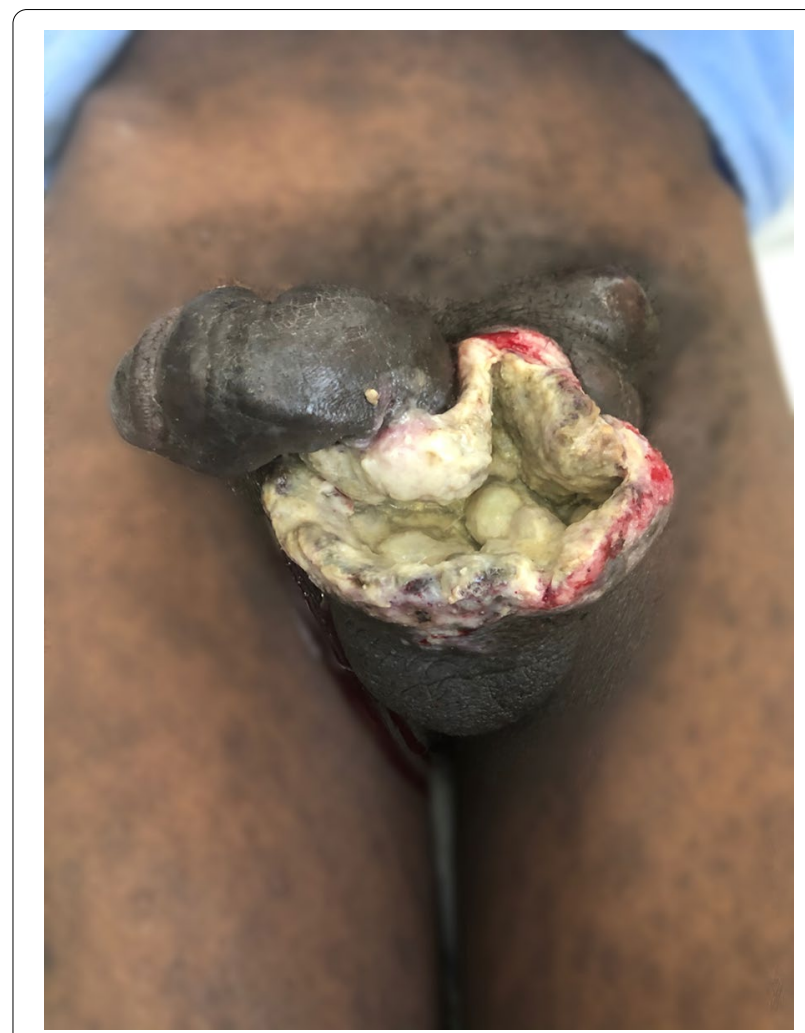

Fig. 2 Photograph showing a fungating, ulcerating, and locally destructive mass with rolled edges involving most of the scrotum and the base of the penis

\subsection{Case 2}

A 45-year-old, African male, presented to the urology unit with a large, foul-smelling scrotal ulcer. The ulcer had dramatically increased in size and severity during the preceding four months. He had been diagnosed with HIV five years earlier. Despite antiretroviral therapy treatment being initiated timeously, he had been known to have defaulted on numerous occasions. His current viral load and CD4 count was 826 copies/mL and 33 cells/uL, respectively. Clinically, the patient appeared chronically ill, wasted and cachectic with a foul-smelling, fungating, ulcerating, and locally destructive mass with rolled edges involving most of his scrotum, the base of the penis and pubic bone (Fig. 2). Also, he had bilateral palpable inguinal lymph nodes, with large fixed nodes in the left inguinal region. Blood work on admission revealed a low haemoglobin $(9.6 \mathrm{~g} / \mathrm{dL})$, normal renal and liver function tests. Urine specimen and wound swab for culture was negative. A punch biopsy of the scrotal lesion confirmed invasive moderately differentiated focally keratinising SCC. The further metastatic evaluation confirmed the presence of metastatic, large para-aortic lymphadenopathy. Palliative, cisplatin-based chemoradiotherapy was initiated. The patient, unfortunately, demised two months after the first presentation.

\section{Discussion}

SCC of the scrotum, first described in 1775, was historically referred to as "Chimney- sweeps' carcinoma" and was the first malignancy associated with occupational exposure to a carcinogen. It affected chimney sweeps who had long-standing exposure to soot, often since early childhood-with boys, as young as eight years old reported having had the disease [2]. With improved occupational health regulations minimising exposure to carbon-based products at the workplace and the obsolescence of the domestic fireplace, scrotal SCC has become a rarity with an incidence of reported as low as 0.35 per $1,000,000$ male persons per year [3]. Over the years, many other risk factors have been identified. These include exposure to carcinogenic compounds, chronic irritation of the area, chronic inflammatory states, human papillomavirus (HPV) infection, poor personal hygiene and smoking $[4,5]$. Iatrogenic factors such as exposure to ionising radiation, radiotherapy, psoralen and ultraviolet $\mathrm{A}$ for psoriasis have also been linked to SCC of the scrotum 
[4]. Although both our patients were HIV positive, the incidence of SCC of the scrotum in this population has not been reported. It is also unclear whether HIV in itself is a risk factor for SCC of the scrotum [6]. Tijani and colleagues reported that three of the four patients seen in Nigeria over two years with scrotal SCC were HIV positive. The state of HIV-induced immunosuppression with the destruction of CD4-helper cells may be an essential factor. CD4-helper cells are responsible for activating natural killer cells that lead to impaired resistance to tumour growth and spread [7]. Besides, HIV is known to be the most substantial risk factor for the development of genital HPV infection. Therefore, HIV infection could be a confounding factor in the development of scrotal SCC [6].

Unlike both HIV-positive patients described here, patients with SCC of the scrotum frequently present 6th and 7th decades. Patients have had long-term exposure to risk factors, and there is usually a latent period of 10-25 years before cancer develops [7].

Our two cases of scrotal SCC differed widely in their presentation. Patient 1 had T1 NO M0 disease and presented with a small $(<2 \mathrm{~cm})$, innocuous-looking lesion of eight years duration. Patient 2 presented with T4 N1 M1 disease and locally destructive mass as well as confirmed metastatic intraabdominal lymph node involvement. Both patients had delayed presentations to a health care professional, which is in keeping with the literature [8].

The extreme sparsity of cases worldwide does not allow for randomised control trials to compare different treatment modalities. Consequently, few guidelines on the management of SCC of the scrotum exist. Each case, therefore, should be managed on its merits. For case 1, surgery was the mainstay of treatment with wide surgical excision of his surgically resectable primary lesions. $\mathrm{He}$ had clinically impalpable lymph nodes, and we decided to defer any inguinal lymph node dissection. After three years of regular follow-up, there was no evidence of recurrence. In the event of a biopsy-proven nodal recurrence in the future, he will need an ipsilateral ilioinguinal lymph node dissection. In a dedicated centre, in expert hands, the addition of a dynamic sentinel lymph node biopsy could serve as an alternative to prophylactic lymph node dissection and avoid the significant morbidity associated with this procedure [9].

Primary closure is usually possible due to the laxity of the scrotal skin. However, suppose there is an extensive tumour, and primary closure is not possible. In that case, the defect can be reconstructed with a local myocutaneous gracilis or adductor minimus myocutaneous flaps, split-thickness skin grafts, heterologous fascia grafts and secondary intention [10]. With more extensive, but still surgically resectable and potentially curable lesions, a hemiscrotectomy may be indicated. In cases where the scrotal contents are involved, they should be removed en bloc. A testis exposed after excessive scrotal skin loss may be orchidectomised, placed in a subcutaneous thigh pouch or transposed into the contralateral scrotal pouch.

Adjuvant radiotherapy, in combination with four cycles of chemotherapy (methotrexate, bleomycin, and cisplatin) has been shown to better disease-free survival with these localised lesions. Our patient, however, declined this adjuvant treatment option [11].

Patient 2 had advanced, metastatic disease. His guarded performance status and limited cardiopulmonary reserve deemed him a poor candidate for surgery. He received cisplatin-based chemoradiotherapy, but demised two months later.

Although targeted molecular and immunotherapies have changed the landscape concerning the treatment of cancers, evidence for their use for SCC of the scrotum is lacking. Biological agents such as anti-epidermal growth factor receptor (EGF-R) and anti-vascular endothelial growth factor receptor (VEGF-R) monoclonal antibodies may be potential therapies in the future [12].

\section{Conclusion}

Early detection and management of patients with SCC of the scrotum are essential. If the diagnosis is delayed, treatment options become limited, and the prognosis is poor. Notwithstanding the rarity of this disease, multicentre trials are needed to provide more precise guidelines as to the optimal management of these patients.

\section{Abbreviations \\ SCC: squamous cell carcinoma; HIV: human immunodeficiency virus; HPV: human papillomavirus; EGR-R: anti-epidermal growth factor receptor; VEGF-R: vascular endothelial growth factor receptor.}

\section{Acknowledgements}

None.

Authors' contributions

$\mathrm{JJ}$ reviewed the literature and drafted the manuscript. KK and $\mathrm{J}$ reviewed and edited the manuscript. All authors read and approved the final manuscript.

\section{Funding}

The authors received no financial support for the research, authorship, and/or publication of this article.

Availability of data and material Not applicable.

\section{Declarations}

Ethics approval and consent to participate

Our institution does not require ethics approval for reporting individual case reports. 


\section{Consent for publication}

Written informed consent was obtained from the both patients for the anonymized information and the accompanying images to be published in this article.

\section{Competing interests}

The authors declare that there is no conflict of interest.

\section{Author details}

${ }^{1}$ Division of Urology, Department of Surgery, Frere Hospital and Walter Sisulu University, East London 5200, South Africa. ${ }^{2}$ Division of Urology, Department of Surgery, Groote Schuur Hospital and University of Cape Town, Observatory, Cape Town 7925, South Africa.

Received: 31 August 2020 Accepted: 28 May 2021

Published online: 06 June 2021

\section{References}

1. Benmoussa N, Rebibo JD, Conan P, Charlier P (2019) Chimney-sweeps' cancer-early proof of environmentally driven tumourigenicity. Lancet Oncol 20(3):338

2. Waldron HA (1983) A brief history of scrotal cancer. Br J Ind Med 40(4):390-401

3. Essid MA, Bouzouita A, Saadi A, Blel A, Chaker K, Chakroun M et al (2018) A case report of scrotal squamous cell carcinoma secondary to chronic urinary irritation. Cureus 10(4). https://doi.org/10.7759/cureus.2430
4. Sarkar D (2019) A systematic review of scrotal squamous cell carcinoma. Eur Med J 7(1):68-74

5. Matoso A, Ross HM, Chen S, Allbritton J, Epstein Jl (2014) Squamous neoplasia of the scrotum: a series of 29 cases. Am J Surg Pathol 38(7):973-981

6. Waight $M$, Jaiganesh T (2016) A scrotal ulcer with degenerating inguinal lymph nodes in an HIV positive patient - infection or malignancy? MOJ Clin Med Case Rep 4(3):72-74. https://doi.org/10.15406/mojcr.2016.04. 00092

7. Tijani KH, Adetayo FO, Akanmu AS, Anunobi CC, Mofikoya BO, Jeje EA (2010) Adult squamous cell carcinoma of the scrotum in HIV positive patients in Nigeria. Afr J Urol 16(2):49-53

8. Huen KH, Nourparvar P, DeCaro JJ, Walsh MD, Issa MM, Ritenour CWM (2013) Scrotal abscess as initial presentation of squamous cell carcinoma. Case Rep Urol 2013:1-4

9. Lam W, Alnajjar HM, La-Touche S, Perry M, Sharma D, Corbishley C et al (2013) Dynamic sentinel lymph node biopsy in patients with invasive squamous cell carcinoma of the penis: a prospective study of the longterm outcome of 500 inguinal basins assessed at a single institution. Eur Urol 63(4):657-663

10. Azike JE (2009) A review of the history, epidemiology and treatment of squamous cell carcinoma of the scrotum. Rare Tumors 1(1):47-49

11. Arai Y, Kinouchi T, Kuroda M, Usami M, Kotake T (1997) A case of scrotal cancer with inguinal lymph node metastasis treated by multidisciplinary modalities including chemotherapy with methotrexate, bleomycin and cisplatin. Acta Urol Jpn 43(9):683-685

12. Dorsey K, Agulnik M (2013) Promising new molecular targeted therapies in head and neck cancer. Drugs 73(4):315-325

\section{Submit your manuscript to a SpringerOpen ${ }^{\circ}$ journal and benefit from:}

- Convenient online submission

- Rigorous peer review

- Open access: articles freely available online

- High visibility within the field

- Retaining the copyright to your article

Submit your next manuscript at $\boldsymbol{\nabla}$ springeropen.com 